\title{
Forms of Students' Intercultural Communication Development in a Multicultural Academic University
}

\author{
Tatiana V. Morozova ${ }^{1}$ \& Elena V. Gabdrakhmanova ${ }^{1}$ \\ ${ }^{1}$ Kazan (Volga Region) Federal University, Kazan, Russia \\ Correspondence: Tatiana V. Morozova, Kazan (Volga Region) Federal University, 420008, Kazan, \\ Kremlyovskaya Street 18, Russia. E-mail: morozov2005@yandex.ru
}

Received: June 15, 2015 Accepted: June 24, 2015 Online Published: June 30, 2015

doi:10.5539/jsd.v8n7p207

URL: http://dx.doi.org/10.5539/jsd.v8n7p207

\begin{abstract}
The objective of the article is to study the concept of "intercultural communication", different ways of its application, the role and related concepts. The article presents basic forms of intercultural communication of students as well as the importance of the process in a multicultural environment of a university. The authors chose a descriptive method of observation and classification of the material as a leading approach alongside with the analysis and synthesis of the data obtained through interviews and polls. The findings suggest that interethnic interaction plays an important role, thus its formation should be integrated into the learning process. The authors also note the role of folk culture in intercultural communication and optimization of a multicultural university in terms of such communication. The research introduces forms of students' intercultural communication in a multicultural university that will contribute to a more effective communication of representatives of different cultures and pupils at multi-ethnic schools.
\end{abstract}

Keywords: intercultural communication, inter-ethnic cooperation, folk culture, multicultural space in a university

\section{Introduction}

\subsection{Importance of the Issue}

In the last decade, due to Russia's expanding international relations, issues of intercultural communication have become particularly interesting.

Expansion of world education, revitalization of academic mobility, introduction of information technology in various spheres of society including education highlight the urgency of the issue of inter-ethnic communication in a multicultural environment, search for new ways that will provide social and psychological comfort of such interaction (Chernikova).

Issues of inter-ethnic cooperation and development of ethnic identity are acquiring special significance in humanities and social sciences. As a result of social, political and economic factors that have led to migration, people are communicating at intercultural level overcoming cultural barriers and getting acquainted with other cultures. Interaction of cultures in modern conditions implies development of cultural relations in various spheres of life - tourism, sports, personal contacts, etc. Any kind of relationship of individuals or groups of people - economic, social, political - will certainly be expressed in the form of specific information (Arutyunov, 1989).

A basic social institution that helps an individual adapt to the changing conditions is the system of education. By emphasising the priority of national values and culture of the peoples, their customs and moral principles of life, education at the same time should ensure the ratio of national and universal. It is one of the necessary conditions for the formation of an educated, intelligent person, free and open to the world, capable to understand and appreciate the uniqueness of other cultures alongside with the development of their own national culture (Fakhrutdinova, 2012).

Today higher education raises a complex of issues dealing with the formation of culture of students' international relations in a multicultural educational environment.

Therefore, mastering the art of intercultural communication is becoming increasingly relevant and important. 
Russian higher institutions are no exception as they possess a unique multicultural educational space - they are dominated by a mixed ethnic composition.

The main issues associated with the development of a culture of students' inter-ethnic relations in the multicultural space of university are the development of axiological mindset of a student by enriching their consciousness with conventional national values of different cultures, training young people in order to expand and deepen their ethnic and cultural outlook, form their tolerance, intelligence of international relations and promote intercultural communication. However, these issues are often solved independently of each other as case studies of some universities, courses or educational programmes.

Multicultural educational space of university is characterised by presence of students of two or more nationalities. The educational role of a multicultural educational environment implies "organization and content of the educational process when there are students from two or more cultures different according to a linguistic, ethnic, national or racial criteria" (Nabivacheva, 2007).

The relevance of this study is justified by an objective necessity for the formation of students' readiness for interethnic communication and life in a multicultural society by creating a multicultural educational environment of university.

The top-priority tasks of modern education appear to be upbringing of respectful attitude towards the historical and cultural traditions of one's own people and formation of a multicultural environment (Karkina, 2014).

In a multicultural environment of university, where formation of culture of international relations among students and promotion of their intercultural understanding are some of the core factors, the efficiency of pedagogical process depends on the willingness and ability of professors to introduce students to cultures and peculiarities of folk cultures. This can be done by teaching various art forms of different nations. In this context, intercultural communication can be regarded as a form of realization of artistic activities and culture of different peoples which for centuries have been enriching each other becoming a source of creative unity (Salakhov, 2013). Therefore, it is important to teach students to understand and accept the culture of other peoples as an enduring value of a national culture, to be aware of the importance of preserving cultural identity and form intercultural communication skills.

\subsection{Status of the Issue}

The concept "intercultural communication" is derived from the concepts "culture" and "communication". The study of intercultural communication is carried out by Cultural Studies. Besides Cultural Studies communication processes are studied by Pedagogy, Sociology, Psychology, Political Science, Linguistics, etc. The starting point of research on intercultural communication was the second half of the $20^{\text {th }}$ century when, in 1954, E. Hall and J. Trager published "Culture as Communication". Here, for the first time, the term "intercultural communication" was used. According to the authors it had to reflect specific relationships between people of different cultures. In 1959, a new book by E. Hall "The Silent Language" was published in which he developed his ideas and showed close relationship between culture and communication. The thesis of E. Hall "Communication Is Culture, Culture Is Communication" caused a lively debate in the scientific community. The merit of E. Hall was the fact that in his studies of intercultural communication he went beyond the traditional linguistic perspective considering communication in a broader cultural context (Yankina, 2005).

With the expansion of spheres of intercultural interaction and the increase of information flows the requirements for specialists in the field of intercultural communication are rising (Bakanova, 2006).

A. Sadokhin believes that "Intercultural communication is a combination of various forms of communication and relationships between individuals and groups belonging to different cultures. The question thus is what and how correlates different cultures. Moreover, the "what" and the "how" do not only suggest each other but can be substantially identical.

Intercultural communication is communication and dialogue between representatives of different cultures which suggests both personal contacts between people and indirect forms of communication (such as writing and mass communication).

Intercultural communication is characterized by the fact that when meeting representatives of different cultures, each of them acts in accordance with their own cultural norms. The definition of intercultural communication as an adequate understanding of two members of a communicative act belonging to different national cultures can be considered a classic (Verschagin, 1990). 
The issue of multicultural education was also studied by American, Canadian and Australian scholars. Multiculturalism was considered by British (J. Lynch) and German (O. Annweiler, R. Holtz, S. Lyuhtenberg, etc.) educators. The works of (P. Adler, R. Norton, D. Lutsker, P. Birdwhistle, etc.) focus on the development of personality that can easily interact in different cultures, that is, an intercultural-oriented personality.

Taking into consideration the findings of the studies reviewed, it should be noted that today in pedagogical theory there is still no coherent picture of the forms of intercultural communication of students in a multicultural educational environment of university.

\section{Materials and Methods}

\subsection{Case Study}

The issue of effective development of intercultural communication of students of a multicultural university necessitates the analysis and the use of new forms of development. We believe that intercultural communication of students should be singled out into an important component of higher education, thus the training of students should follow the pattern of the dialogue of cultures while studying their own culture and enhance their ability to penetrate into the cultural values of other nations, promote tolerance to get acquainted and learn more about the cultures of other nations.

Historically, the city of Kazan (Russia) has been a multicultural environment the national component of which has not changed. The Republic of Tatarstan is home to 167 nationalities.

The multinational peoples of the Republic of Tatarstan unite 3.8 million people who identify themselves as 115 ethnic communities. According to the 2002 census, the largest group are the Tatars $-2,116,000$ people (52.9\%). The Russians have always occupied the second place - 1,492,602 people (39.5\%). The third place is taken by the Chuvash $-126,532$ people (3.3\%). The number of Udmurts, Ukrainians, Mordovians, Mari and Bashkirs is over 10,000 people. In recent decades, as a result of intensified migration processes in Tatarstan, there have been formed relatively numerous (several thousand) groups of immigrants from the former Soviet republics (Azerbaijanians, Armenians, Uzbeks, Tajiks, Kazakhs, Georgians, Moldovans, Turkmens) and somewhat smaller in size (a few hundred) national groups from the regions of the Russian Federation, as well as from abroad (Turks, Vietnamese, Arabs, and others).

Kazan Federal University is one of the best universities in the country. Students from Samara, Orenburg, Ulyanovsk and Kirov regions, the republics of Udmurtia, Chuvashia and Bashkortostan study here. Today the University trains about 1,400 international students and in the coming years this number will increase at least threefold.

This fact gives us reason to believe that the multicultural educational environment of Kazan Federal University is multicultural and the University itself is a multicultural university. In this regard, it is necessary to develop the University students' intercultural communication in various forms including the potential of their own folk culture since among all the spheres of interaction the cultural sphere is the least problematic and the most open one and can serve as the basis of further peaceful cooperation.

Folk art connects material and spiritual relations of young people with the world, filling them with the help of spiritual and practical activities by subject-valuable relations. At the same time the study of folk art requires a special approach, both from historical, cultural, and pedagogic positions (Salakhov, 2013).

Intercultural communication is embodied in different forms of artistic activity. Taking into consideration the existing world experience in representing the artistic expression of different nations as a means of expression of aesthetics when for centuries cultures and forms of artistic activities enriched each other and became a source of creative unity, the Graduate School of Arts named after Salih Saidashev at the Institute of Philology and Intercultural Communications of Kazan (Volga Region) Federal University established a multicultural model of development of artistic culture of a personality through art.

This model consists of various forms of intercultural communication of students. One of them is a literary and artistic salon "Renaissance". Today, the greatest value of the modern world is the value of cultural diversity. The meetings of the literary and artistic salon are often devoted to the issues of national art, for example, "In the depth of unrecorded time" (September, 2011), "Shamail. The soul of the people" (November, 2011), "Back to the roots" (April, 2012). At meetings students have fruitful discussions on the critical issues of preservation and development of folk culture: ethnic heritage of the Tatar people and its embodiment in professional arts, necessity for promotion of little-known phenomena of national culture, role of national culture and art in the modern world. The interaction of art and authority in national culture has special poignancy. Until recently, turning to a national theme was not encouraged and required a certain position of the artist. Now, on the contrary, 
the desire to meet the political situation stimulates interest in national art but does not always provide the artistic result. Only through a creative individual and his / her spiritual world, they become national - through the pattern, rhythm and expressive music. In the four years of its existence, the literary and art salon "Renaissance" has become a full-fledged cultural phenomenon of Kazan. It focuses on addressing and bridging gaps (cultural, communication, generational, etc.) and turns into a conductive layer that unites everyone: teachers and students, masters and students, professionals, experts and amateurs into a single unit (Salakhov, 2013).

The curriculum includes a block of musical, artistic and theoretical courses such as Folk Art, History of Tatar Music, History of Tatar Art, Music of the Peoples of the Volga Region, Arts and Crafts. These courses are included in the National Regional Component. Doing these courses students learn about the traditions of the peoples living in Russia and Tatarstan. The repertoire of the students' choir includes the works of composers of different nations, arrangements of folk music, programmes for individual training in classes of solo singing, conducting, instrumental performance, including the works of Russian and foreign classical composers as well as the works of composers of the Volga region (Tatar, Udmurt, Chuvash, Mordovian, Mari and other nationalities).

By attending exhibitions of professional and folk artists students get the idea of culture, traditions and ways of contemporary fine arts of Tatarstan.

Thus, the study of folk art does not only develop students' creative aspirations but also introduces them with the culture of their people and the culture of the peoples of the nearest national environment. It is one of the main forms of formation of intercultural communication.

\subsection{Research Objectives}

The unique feature of multinational Republic of Tatarstan was considered in the Declaration of State Sovereignty of Tatarstan proclaimed in 1990. The document clearly established the principle of equality of rights and freedoms of all citizens, regardless of their ethnicity and other social characteristics. This principle was further reflected in the Constitution of the Republic of Tatarstan, as well as in the public acts of the Republic.

The Assembly of the Peoples of Tatarstan maintains this unity. Annually it hosts such major forums as the Congress of the Peoples of Tatarstan, the World Congress of Tatars and other various multinational republican youth sports and folk festivals. The republic's orientation towards tolerance including intercultural interaction can be easily explained by the ethnic character traits of the peoples of Tatarstan. They especially respect skills, professionalism, education, science, and culture which can also be proved by the liberal intelligentsia of the republic.

The problem of inter-ethnic cooperation is exceptionally important for the republic and for the whole of the Russian Federation too because all the major aspects of economic, political, social and spiritual spheres of society are closely connected with the ethnic factor. The universities of Tatarstan are no exception. The Institute of Philology and Intercultural Communication, KFU, works on the formation of students' intercultural communication in various forms bearing in mind that intercultural interaction of the peoples of Tatarstan is a historically conditioned process which developed their own forms of interchange and tolerance.

\subsection{Research Methods}

We believe that the use of various forms of cultural interaction, based on the study of folk art will be a favourable basis for the development of intercultural communication of students of a multicultural university.

To give a more detailed analysis of the impact of the study of folk culture on intercultural interaction of students, to determine the degree of social tension in order to predict the formation of patterns of action to comfort interethnic interaction, a study was conducted in 2014.

While working on the study, the following methods were used:

- Analysis of psychological, educational, scientific and practical literature on the issue;

- Generalization of innovative pedagogical experience in the multicultural environment of Kazan universities;

- Interviewing, collecting, analyzing and summarizing data.

The theoretical and methodological basis of the study were primarily the works of domestic and foreign researchers, such as Y, Arutyunyan, L. Drobizhieva, A. Susolokov, V. Chernikova, and S. Arutyunov, professors of Kazan (Volga Region) Federal University, such as R. Salakhova, R. Salakhov, S. Karkina, L. Khabibulina, R. Khurmatullina, and R. Fakhrutdinova. 


\subsection{The Actual Study Material}

The methodological framework of this study was a quantitative type of methodology, particularly, the method of "polling" that studies the state of intercultural interaction of university students, determines the degree of social tension in order to predict the formation of patterns of action to comfort interethnic interaction, and explores the impact of folk culture on intercultural communication of students. This method allowed us to interpret the facts of social reality in the context of intercultural communication, to determine their nature and inner meaning. The technology of implementation of the method of "survey" is a structured questionnaire in which the procedure "question-answer" is strictly regulated. This study used a quota (stratified) selection based on the construction of a qualitative model of statistical universe and further selection of units of observation in the sampling frame using available models.

To study the state of intercultural interaction of students and identify possible ethnic tensions, we conducted a poll that predicted the actions leading to the formation of the model of comfortable interethnic interaction at the Institute of Philology and Intercultural Communication of Kazan Federal University. The students had to describe the situation of inter-ethnic interaction, state their attitude to the other students of different nationalities studying in the Institute and express their opinion on the forms of intercultural communication practised in the Institute. The survey involved 216 students, the average age of which was 22.4, from 19 to 24 years old.

\section{Results}

The results show that 72 per cent of the pollees pay attention to representatives of other nationalities in their daily life. 20 per cent do not attach importance to this aspect. These results were proved by the other questions (How can you describe your relations with students of other nationalities?) and the answer "I do not communicate with them at all" was given only by 7.5 per cent. In turn, 92.5 per cent have friendly and trust relations with representatives of other nationalities.

The question "Do you willingly communicate with other peoples?" was given a "Yes" answer by 47 per cent. 40 per cent chose "Very likely" adding that they can communicate with people of different nationalities, learn the traditions of other cultures, take part in exchange programmes. Only 5 per cent said "No" and 5 per cent answered "Very unlikely".

Speaking of ethnic conflicts in everyday life, the study revealed that 5 per cent and 6 per cent of respondents chose the answer "Yes", they experienced them, and "very likely" respectively, while 89 per cent of the pollees felt conflicts in everyday communication on ethnic grounds. The task of a university then is to eliminate such conflicts and establish a model of comfortable interethnic interaction. The vast majority of the respondents (99.5 per cent) chose a positive answer to the question "Do you know your culture well?"

The question "What exactly do you know about your culture?" was answered in the following way: "national cuisine" (22 per cent), 56 per cent of the students know "national holidays, customs and traditions" of their people. The answer "history of my people" was chosen by 5 per cent. 17 per cent of the pollees chose the "language" of their people.

The question "Do you know the culture of other nations well?" was answered as follows: "Yes" - 5 per cent, "Rather well" - 47.5 per cent, "No" - 10 per cent, "Very badly" - 32.5 per cent. The study shows a low level of knowledge of the culture of other nations, however, the question "Would you like to know more about the culture of other nations?" received 62.5 per cent of the "Yes" answers.

Taking into consideration the fact that culture of international relations is a complex process that uses a common range of special knowledge and skills, and the fact that the motivational component is extremely important too, lack of awareness of the activities where students can get acquainted with other cultures is one of the important issues and requires search of new forms of communication and involvement of all the interested persons into the dialogue of cultures.

The second proposed answer was "Very likely" that was favoured by 27.5 per cent of the students. These students are internally ready to establish international contacts based on the knowledge of national mentality, traditions and values of other cultures. The third option "No" was chosen by 2.5 per cent.

Answering the question "What university activities will help learn more about other nationalities?" 10 per cent said that it is necessary to organize language courses. More than half of the pollees favoured "joint cultural activities" (86 per cent).

Analyzing the students' responses, we can say that their attitude to the multinational composition of the university cannot be considered perfect but it is more or less favourable. More than half of the students are 
tolerant to the representatives of other nationalities, however, about a quarter of the students take an intermediate position. This group of respondents has not formed any opinion on these issues yet and depending on the actions of the pole will take a position. Besides, the poll revealed what is needed for better understanding of the issue.

Thus, one of the most popular forms of development of students' intercultural communication in a multicultural university will be considered systematic work on the formation of common cultural competences in terms of tolerant relations. It is absolutely essential for representatives of various national and ethnic groups to join in the activities aimed at the introduction and study of the culture of different peoples.

\section{Discussions}

The educational and mobilization role of the team of students and professors of the Institute of Philology and Intercultural Communication, aimed at the development of the culture of inter-ethnic communication, consists of socio-educational cooperation, i.e. assistance to students of different nationalities to adapt to the multicultural environment of the university with regard to their ethnic specificity. The content of the courses, aimed at the study and preservation of national traditions of the peoples of the Republic of Tatarstan, is a socio-educational factor of efficiency of the process of co-creation of students, improving the internal culture and national education of representatives of different nationalities. Awareness of the importance of cultivating the culture of inter-ethnic relations on a personal level is another socio-educational factor since in modern conditions a person remains national, has a stable national identity and national and psychological orientation in their work. Thus, all the students and professors become a stable multi-ethnic community reflecting the collective image of "we".

It is impossible to establish the atmosphere of creativity without respect for "foreign" culture. Daily contacts of students of different nationalities form their understanding of each other, create goodwill and respect regardless of their ethnicity, and teach them to be tolerant to the traditions and cultural practices, religious beliefs of other people.

Culture of interethnic interaction in a multicultural space can be defined as a set of most common moral and psychological standards guaranteeing free creativity in the learning process in an academic university.

Such awareness is an essential element of educational work of university and the strategy for creating multicultural space in university, mastering and using certain norms of behaviour, ways and forms of friendly relations and interaction between students of different nationalities.

\section{Conclusion}

Modern society that is characterised by rapidly changing patterns, types and forms of cultural cooperation places great importance on active forms of popular cultural practices. Formation of intercultural communication by means of folk art contributes to solving a major social objective aimed at ensuring a constructive intercultural dialogue. It also contributes to the formation of artistic culture, acquisition of aesthetic experience, development of spiritual and moral position of a student in a multicultural university. While studying folk art and ethnic traditions through the prism of their own spiritual experience people are able to understand the "other world", tolerate "other people" and learn how to empathise with them. Thus, each student in the course of their work is open to perceive other people's cultural experience. At the same time they are ready to share their own culture with other students. Such attention to the cultures of other peoples creates conditions for "cultural interaction" and "intercultural communication" in the multicultural environment of university. The mechanism of formation of intercultural communication must include such elements as stable and wide exchange of information, social optimism, comprehensive inter-ethnic interaction and as a result develop understanding between peoples while studying folk culture.

\section{Acknowledgments}

The work is performed according to the Russian Government Program of Competitive Growth of Kazan Federal University.

\section{References}

Arutyunov, S. A. (1989). Peoples and Cultures: Development and Interaction. Moscow.

Arutyunyan, Y. V., Drobizhieva, L. M., \& Susolokov, A. A. (1998). Etysociology. Moscow, 112.

Bakanova, Yu. V. (2006). Forming the Basics of Intercultural Communication of Students in Learning a foreign Language. Coll. Scientific. Works of Young Scientists. UralGAFK. Ed. 5. Chelyabinsk: UralGAFK, 16-17. 
Chernikova, V. E. (n.d.). Inter-Ethnic Communication in the Context of a Modern Multicultural Space. Retrieved from http://cyberleninka.ru/article/n/mezhetnicheskaya-kommunikatsiya-v-kontekste-sovremennogo -polikulturnogo-prostranstva

Fakhrutdinova, R. A. (2012). Organization of Intercultural Communication in a Multicultural Space of University. Materials of the International Scientific and practical Conference. Kazan Federal University, Institute of Philology and Arts. Kazan: Fatherland, 504.

Karkina, S. V., Khabibulina, L. F., \& Khurmatullina, R. C. (2014). Approach to the dialogue of cultures in the musical and aesthetic education of undergraduates. Life Science Journal, 11(10s), 296-299.

Khabibulina, L. F. (2014). Cultural Identity of a Person in the Polycultural Space Terms: Its Social Aspect Life. Science Journal, 11(11), 248-251.

Nabivacheva, E. A. (2007). Preventing Maladjustment of Foreign Students in the Educational Space of the Russian University. PhD Thesis. Khabarovsk.

Salakhov, R. F., \& Salakhova, R. I. (2013). Literary and Art Salon "Renaissance" as the Active Practice of Formation of the Artistic Culture of the Individual. Multicultural Education Area of the Volga Region: the ways and forms of integration: Sat. nauch. trudov. intern. nauchn.-prakt. konf. Kazan, 554-558.

Salakhova, R. I., \& Salakhov, R. F. (2013). People's Artistic Creativity as a Factor of Valuable Relation to the Motherland. Art and Art Education in the Context of Intercultural Communication: Intern Materials. Nauchn.-prakt.konf. Kazan, 614-618.

\section{Copyrights}

Copyright for this article is retained by the author(s), with first publication rights granted to the journal.

This is an open-access article distributed under the terms and conditions of the Creative Commons Attribution license (http://creativecommons.org/licenses/by/3.0/). 